In a recent investigation on 31 male twin pairs cardiovascular reactions during stressful psychiatric interview were studied. ${ }^{5}$ It was found that intrapair variance did not differ between monozygotic and dizygotic pairs at rest either for systolic or for diastolic blood pressure, but during psychological strain the intrapair variances were significantly less within monozygotic than dizygotic pairs for both measures of blood pressure. These data imply that a significant genetic influence on the variability of blood pressure might first be revealed in stressful situations.

It was finally stated in your leading article that "clearly the best precaution a newborn baby can take over its arterial blood pressure and therefore its cardiovascular risk in later life is to choose its parents carefully." This hopeful piece of advice could be supplemented with another, more hopeful one: learn to cope with stressful situations.

Department of Medicine,

Serafimerlasarettet,

${ }^{1}$ Lundman, T, Acta Medica Scandinavica, 1966, supp

455.
2 Liljefors, I, Acta Medica Scandinavica, 1970, suppl

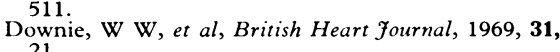

21.

Mathers, J A L, Osborne, R H, and de Geor
American Heart fournal, 1961, 62, 634.

de Faire, U, and Theorell, T, Programme of Second International Congress of Twin Studies, Washington, DC, 1977, p 24.

\section{Tuberculosis of the female genital tract}

SIR,-I read with interest your leading article on this subject (4 February, p 260). In East Anglia tuberculosis of the female genital tract appears to be excessively rare, possibly due to be absence of a significant immigrant population.

I would agree with you that laparoscopy is contraindicated if active tuberculous pelvic disease is suspected, but I think one should realise that in such populations as ours where there is no antecedent history of tuberculosis the diagnosis will be rarely made other than by laparoscopy. In 10 years I have diagnosed only three cases of tuberculosis, all by laparoscopy, which was carried out in two of them for infertility and in the third for abdominopelvic pain. In only one of the three, despite repeated attempts, was the responsible organism grown from endometrial curettings at the appropriate phase of the menstrual cycle. In the other two cases attempts to grow the organism from endometrial curettings failed, but it was grown from peritoneal biopsy specimens.

I would suggest that in future the diagnosis of genital tract tuberculosis in women is more likely to be made by laparoscopic examination than any other.

Cambridge

R E RoBINSON

SIR,-I wish to comment on your leading article on this subject (4 February, p 260). These comments are based on my personal experience of the management of more than 600 women with tuberculosis of the pelvic organs during the past 27 years.

I would agree that treatment of gynaecological tuberculosis is straightforward and that the drug regimens used so successfully for pulmonary lesions should also be applied to genital tuberculosis. Before one can assume that a patient has been cured by drug treat- ment, however, a long-term and thorough follow-up is essential. In some patients the tuberculous pelvic lesion recurs five or more years after the end of the drug course. The longest gap between treatment and recurrence in my own series is 19 years. Consequently it is entirely wrong to assume that a patient has been cured of her tuberculous condition after one or two post-treatment examinations.

In my most recent publication ${ }^{1}$ I discussed my experience of drug treatment of female genital tuberculosis during a 25-year period. In all groups, apart from those treated with the newer antituberculosis drugs, there was a substantial failure rate, the lowest being $12.3 \%$ in patients treated with streptomycin, PAS, and isoniazid for 18 months or two years. I have to date had no failures in the patients treated with streptomycin, ethambutol, and isoniazid or in the current group treated with rifampicin, ethambutol, and isoniazid. It is much too early, however, to compare these results with those in patients treated with earlier drug programmes.

No mention is made of the place of surgery in the treatment of tuberculosis of the female genital tract. The main indications for surgery are persistence or recurrence of the tuberculous condition, the development of pelvic masses, and the development of distressing symptoms particularly pelvic pain. In a previous article I presented a preliminary report on the indications for surgery. At that time $20 \%$ of my patients followed up required operative treatment. The results of pelvic clearance performed under antituberculosis drug cove were uniformly satisfactory. A further pape on this question is at present being prepared.

In your leading article it is stated that the outcome of drug treatment of gynaecologica tuberculosis is nowhere as well documented as it is in pulmonary disease. I am not in position to say whether or not this is so and gynaecological tuberculosis is certainly a fairly uncommon condition. I have, however, published more than 20 articles in this field in which details of a careful long-term followup are given.

Glasgow

ARTHUR M SUTHERLAND Sutherland, A $\mathrm{M}$, British fournal of Obstetrics and
Gynaecology, $1977, \mathbf{8 4}, 881$.
Sutherland, A M, Acta Obstetricia et Gynecologica
Scandinavica, 1965, 44, 163.

\section{Carbon dioxide-dependent}

\section{Escherichia coli}

SIR,-In view of the recent interest in carbon dioxide-dependent strains of Staphylococcus aureus (24 September, p 830) and Klebsiella spp (4 February, p 300) we would like to report the isolation of a $\mathrm{CO}_{2}$-dependent Escherichia coli $\mathrm{O} 75 \mathrm{~K}$ ?.

The initial isolate was from a midstream urine specimen containing large numbers of organisms on microscopy that failed to grow on cysteine-lactose electrolyte-deficient (CLED) medium incubated in air but grew when the urine was cultured on blood agar anaerobically, though not in air. It was thought at first to be an anaerobe. Isolation of a typica $E$ coli from a blood culture from the same patient taken two days after the urine culture prompted further investigation into the urinary isolate. The blood culture isolate had been recovered after subcultures on to blood agar incubated in $10 \% \mathrm{CO}_{2}$ and anaerobically. The organisms in the urine and blood were identical and failed to grow in a candle jar, though they grew well in a $\mathrm{CO}_{2}$ incubator and anaerobically (with $10 \% \mathrm{CO}_{2}$ ). An identical strain reappeared in the patient's blood and urine 26 days later, still $\mathrm{CO}_{2}$-dependent.

Such organisms are probably rare; this is the first we have encountered in 240 strains of $E$ coli isolated from blood and our procedure for the investigation of sterile bacteriuria and pyuria has never resulted in the isolation of $\mathrm{CO}_{2}$-dependent coliforms.

\section{SUSANNAH EYKYN} IAN PHILlips

Department of Microbiology,

St Thomas's Hospital Medical Schoo!, London SE1

\section{Needle tracheostomy for acute upper airway obstruction}

SIR,-In acute upper respiratory obstruction when intubation is not possible owing to lack of equipment or because the patient has complete laryngeal obstruction entrance to the respiratory tract through the cricothyroid membrane can be life-saving.

Dr T H Lee (4 February, p 281) mentions the use of a large-bore Medicut cannula introduced with its needle through the cricothyroid membrane, after which the needle and syringe are withdrawn and oxygen administered "over the cannula." In hospital in good light the cannula can be so used. In emergencies in general practice, particularly in bad light, there is always a possibility of the cannula disappearing into the trachea. It is therefore of practical advantage, having removed the syringe from the cannula, to detach the needle, take out the piston, and then reattach the barrel of the syringe to the cannula. This gives a wider aperture for the administration of oxygen. In the past a curved cricothyrotomy cannula with an introducer was quite frequently used in the treatment of acute respiratory obstruction. It is now coming back into use. The instrument available is an Abelson cricothyrotomy cannula and it is manufactured by Becton Dickinson and Co, an American firm whose UK office is in Wembley, Middlesex.

ROSEMARY H M ADAMS

Accident and Emergency Department,

Norfolk and Norwich Hospital,

Norwich

SIR,-Dr T H Lee gives an interesting account of needle tracheostomy (4 February, p 281), an operation which may indeed be life-saving. It is, however, not a safe one to rely on in general, as a needle or intravenous cannula is too easily blocked by blood or bronchotracheal secretions.

I share his rejection of formal tracheostomy. In an emergency it is too slow and too bloody. It should, however, be replaced (in my opinion) by laryngostomy, which is as quick as the needle method and permits tracheal suction, proper intubation, and positive pressure ventilation.

Laryngostomy was an operation devised in the days of laryngeal diphtheria and abandoned because of the disastrous scarring which developed at the operation site as a result of diphtheritic infection. If it is carried out according to the directions given in Accidents and Emergencies ${ }^{1}$ and not maintained for more than 48 hours, by which time it will be clear whether a formal tracheostomy is 